\title{
EVALUATION OF THIN KEVLAR-EPOXY FABRIC PANELS SUBJECTED TO SHEAR LOADING
}

\author{
Donald J. Baker \\ Vehicle Structures Directorate \\ U. S. Army Research Laboratory \\ Langley Research Center \\ Hampton, VA
}

Presented at the 37th AIAA/ASME/ASCE/AHS/ASC Structures, Structural Dynamics, and Materials Conference

Salt Lake City, UT

April 15-17, 1996

AIAA Paper 96-1367 


\title{
EVALUATION OF THIN KEVLAR-EPOXY FABRIC PANELS SUBJECTED TO SHEAR LOADING
}

\author{
Donald J. Baker * \\ Vehicle Structures Directorate - ARL \\ NASA Langley Research Center \\ Hampton, VA 23681
}

\begin{abstract}
$\underline{\text { Abstract }}$
The results of an analytical and experimental investigation of 4-ply Kevlar-49-epoxy panels loaded by in-plane shear are presented. Approximately onehalf of the panels are thin-core sandwich panels and the other panels are solid-laminate panels. Selected panels were impacted with an aluminum sphere at a velocity of either 150 or $220 \mathrm{ft} / \mathrm{sec}$. The strength of panels impacted at $150 \mathrm{ft} / \mathrm{sec}$ was not reduced when compared to the strength of the undamaged panels, but the strength of panels impacted at $220 \mathrm{ft} / \mathrm{sec}$ was reduced by 27 to 40 percent. Results are presented for panels that were cyclically loaded from a load less than the buckling load to a load in the postbuckling load range. The thin-core sandwich panels had a lower fatigue life than the solid panels. The residual strength of the solid and sandwich panels cycled more than one million cycles exceeded the baseline undamaged panel strengths. The effect of hysteresis in the response of the sandwich panels is not significant. Results of a nonlinear finite element analysis conducted for each panel design are presented.
\end{abstract}

\section{Introduction}

Minimum-thickness laminates in lightly loaded fuselage skins have more than adequate strength for the applied loads although the resulting bending stiffness may only be marginal for the design requirements. An economical way to increase the bending stiffness with a minimum weight penalty and manufacturing cost is to use a structural concept that is based on sandwich construction. Considerable work has been performed on buckling-resistant (thick-core) sandwich panels representative of transport aircraft. A limited amount of unpublished research has been conducted on thin-core sandwich panels, but comparisons have not been made with solid-laminate panels.

The present paper presents the analytical and experimental results of a study of Kevlar-epoxy panels loaded by in-plane shear. The 4-ply-thick, 8-inch-wide by 13 -inch-long panels are made from style 285 Kevlar-49 fabric epoxy material. Approximately onehalf of the panels also have a thin middle layer of polymethacrylimide foam to form a mini-sandwich panel. A nonlinear finite element analysis for each design configuration was used to determine the initial linear buckling load and geometrically nonlinear responses. The present paper presents results that represent the postbuckling strength and fatigue life of undamaged and damaged solid-laminate and thinsandwich panels. Fatigue life is determined by cycling the panels through the buckling load and into the postbuckling load range. The results for the thinsandwich panels are compared with the results for the solid-laminated shear panels.

\section{Panel Design and Fabrication}

Two different 8 -inch-wide by 13 -inch-long panel designs were considered in this investigation. One design is a solid laminate with four plies of $\pm 45^{\circ}$, style 285 Kevlar-49 fabric impregnated with 5208 epoxy resin. This panel design is refered to as a solid panel in the present paper. The other panel design is a

\footnotetext{
- Aerospace Engineer, Structural Mechanics Branch. Copyright $(\odot$ by American Institute of Aeronautics and Astronautics, Inc. No copyright is asserted in the United States under Title 17, U.S. Code. The United States Government has a royalty-free license to exercise all rights under the copyright claimed herein for Governmental Purposes. All other rights are reserved by the copyright owner.
} 
sandwich construction which has a layer of polymethacrylimide foam as the middle layer of the panel design. This design is refered to as a sandwich panel in the present paper. The total thickness of the solid panel varies from 0.033 to 0.034 inches and the thickness of the sandwich panel varies from 0.067 to 0.069 inches. The individual test panels were cut from large laminates and steel load introduction tabs were secondarily bonded to the panel edges to provide the 8inch-wide by 13-inch-long test area (see figure 1).

Material properties used in the analysis were determined by testing coupons manufactured from the same material batches that were used for the panels. The averages of five replicate tests for each material property are summarized in Table 1 and typical stressstrain curves for the material are shown in figures 2 and 3.

\section{Test Procedures}

All tests were performed at room temperature in the asfabricated condition. No environmental conditioning was performed on any specimen. The 8-inch-wide by 13-inch-long shear panels were installed in an in-plane shear test fixture (reference 1). The fixture and the load introduction frame are shown in figure 4 installed in a servo-hydraulic test machine with a minimum $30,000 \mathrm{lb}$. capacity and adequate clearance between the test-machine loading heads to accept the fixture.

Loads were applied to the static test panels at the rate of $600 \mathrm{lbs} / \mathrm{min}$ or $46 \mathrm{lbs} / \mathrm{in} / \mathrm{min}$ while the cyclically loaded panels were cycled at a frequency of $3 \mathrm{~Hz}$ to a predetermined maximum load. Maximum loads for the cyclically loaded tests were selected so that failure would occur at approximately one million cycles. Prior to cyclic loading, each panel was statically loaded to the maximum load to determine the static response. The minimum load was approximately 10 percent of the maximum load. Panels that did not fail during cyclic loading were subsequently loaded to failure to determine their residual strength.

Loads were applied to three sandwich panels (one undamaged and two damaged) at increasing amplitudes (low cycle fatigue) to determine if there was a hysteresis effect in the panel response. The sandwich panels were cyclically loaded five times with the maximum loads of $75,122,167,194$ and $226 \mathrm{lbs} / \mathrm{in}$ before loading the panels to failure.

Prior to testing, selected panels were installed in the in-plane test fixture and impacted using a low-velocity air gun apparatus. The gun fires 0.50 -inch-diameter aluminum spheres with a mass of $0.0065 \mathrm{lb}$. at a selected velocity. The velocities selected were 150 $\mathrm{ft} / \mathrm{sec}$ and $220 \mathrm{ft} / \mathrm{sec}$. The $150 \mathrm{ft} / \mathrm{sec}$ velocity produces damage in the panels while the $220 \mathrm{ft} / \mathrm{sec}$ velocity perforated the panels. The impact site was 3.0 inches from a corner on a diagonal as shown in figure 1. After impact the panels were inspected to provide a measure of the impact damage area. The damaged panels were installed in the test fixture so that the impact damage was located on the tension diagonal for testing.

All static test panels and selected fatigue test panels had back-to-back rosette strain gages installed in the center of the panel as shown in figure 1. Out-of-plane displacements for the panels that were cyclically loaded were determined by five linear variable displacement transducers (LVDT) located at the panel center and at quarter points along each centerline. LVDT's were not used to measure out-of-plane deflections for the static test panels. The load, strain, out-of-plane displacements and test-machine head displacement were recorded with a computer-controlled data acquisition system for each test.

\section{Analysis}

A finite element analysis was conducted for each design configuration using the STAGS nonlinear analysis code (reference 2 ) to determine the initial buckling load and geometrically nonlinear responses of the panels. STAGS is a finite element code for the general-purpose analysis of shell structures of arbitrary shape and complexity. The STAGS finite element model for the test specimens is shown in figure 5. A 4node quadrilateral shell element, STAGS element 410, was used in the analysis. The test fixture is also included in the model to provide the correct kinematics and boundary conditions for the test panels. The predicted initial linear buckling load is $16 \mathrm{lbs} / \mathrm{in}$ for the solid panels and $158 \mathrm{lbs} / \mathrm{in}$ for the sandwich panels. The predicted out-of-plane displacement results, $w$, from a nonlinear STAGS analysis of a four-ply Kevlarepoxy solid panel are shown in figure 6 for $N_{x y}=850$ $\mathrm{lbs} / \mathrm{in}$. This load is over 50 times greater than the predicted linear buckling load. At $850 \mathrm{lbs} /$ in of load, the nonlinear analysis predicts six half-waves with two more half-waves starting to appear in the corners oriented at approximately $45^{\circ}$ to the side of the test area as shown in figure 6 . The predicted $\varepsilon_{\mathrm{xx}}$ surface strain, where $\mathrm{x}$ is a material coordinate that is also parallel to the buckle pattern, is shown in figure 7 for 
$\mathrm{N}_{\mathrm{xy}}=850 \mathrm{lbs} / \mathrm{in}$. The maximum strain is $.013 \mathrm{in} / \mathrm{in}$ along the crest of the deepest buckles.

\section{$\underline{\text { Results and Discussion }}$}

A summary of the experimental results of the 39 panels tested are given in Tables 2,3 and 4. A summary of the results from the static and cyclical load tests of the solid panels is given in Table 2. A summary of the results from the static and cyclical load tests of the sandwich panels is given in Table 3. A summary of the results from the low cycle fatigue tests of three sandwich panels is given in Table 4. The location of the failures in the panels are shown pictorially in figure 8 where each letter indicates a failure location. The failure locations in each panel are summarized in column 8 of Tables 2 and 3 and column 5 of Table 4 .

\section{Solid Panels}

Before testing, selected panels were impact damaged as noted previously. C-scan results for a typical damage site of the solid panels are shown in figures 9 and 10 for $150 \mathrm{ft} / \mathrm{sec}$ and $220 \mathrm{ft} / \mathrm{sec}$ impact velocities, respectively. The damage areas for solid panels impacted at $150 \mathrm{ft} / \mathrm{sec}$ are than less 0.06 square inches as shown in figure 9. The damage areas for the solid panels perforated with a 0.50 -inch-diameter sphere are less than 1.0 square inch as shown in figure 10 .

Determination of the initial buckling load of the solid panels is difficult. Only six of the eleven undamaged panels had a buckling load that could be defined. The buckling loads range from 12 to $25 \mathrm{lbs} / \mathrm{in}$ with an average of $20 \mathrm{lbs} / \mathrm{in}$. This average buckling load is 125 percent of the buckling load predicted by linear analysis. The panels generally started deforming outof-plane with the application of load and continued to form a buckle pattern in the center of the panel that was oriented at $45^{\circ}$ to the side of the test area. As the load increased, the existing buckles increased in depth and more buckles started to form at opposite corners which moved toward the center. A typical out-of-plane deformation pattern for the solid panels (Panel SL3) is shown in figure 11 and has developed six half-waves and two more half-waves appear to be starting to form in the corners for an applied load of $851 \mathrm{lbs} / \mathrm{in}$. This deformation pattern compares well with the predicted deflections shown in figure 6 . The strain gage results for Panel SL1 are shown in figures 12 and 13. Strain gages 1 and 4 (figure 12) are parallel to the buckle pattern and indicate a tensile strain from the start of loading up to failure at approximately $0.010 \mathrm{in} / \mathrm{in}$. The dashed line in figure 12 is the predicted strain from the
STAGS nonlinear analysis. Good correlation is demonstrated between the experimental strain and the predicted strain. The strain at panel failure is approximately 60 percent of the material allowable of $0.017 \mathrm{in} / \mathrm{in}$ (See Table 1). The strains shown in figure 13 are for strain gages 3 and 6 which are normal to the buckle pattern. The strain gages initially indicate compression, as expected, and at approximately 20 $\mathrm{lbs} / \mathrm{in}$, the strain recorded by gage 3 reverses direction to indicate that the buckling load has been reached. It appears from the load-strain curves that a local failure of the panel may have occurred at 150 to $200 \mathrm{lbs} / \mathrm{in}$. The load-strain curve (figure 13) is shown in figure 14 with an expanded scale which shows finer detail of the strain reversal. Strains computed in the STAGS nonlinear analysis are also shown in figure 13 as a dashed line. The predicted strains shown in figure 13 are at the center of an element and are approximately 0.3 inches from the location of the strain gage in the test. Good correlation is demonstrated between the experimental strain and the predicted strain. A diagonal tension field, where one diagonal is in tension and the other diagonal is in compression, has developed in these solid panels after buckling occurs. These strain results are typical of all of the static tests of the solid panels.

Plots of the test-machine head displacement as a function of load are shown in figure 15 for six of the static test panels. The slopes of these curves are the same for loads greater than $200 \mathrm{lbs} /$ in indicating that the panel in-plane shear stiffnesses are the same. The damage to the panels did not cause a change in the inplane stiffness. All curves have a small change in slope at approximately 150 to $180 \mathrm{lbs} / \mathrm{in}$ indicating that some change has occurred to the response of the panels. A summary of the static strengths of the solid panels is shown in figure 16. The average strength of the panels impacted at $150 \mathrm{ft} / \mathrm{sec}$ is the same as the average strength of the undamaged panels while the average strength of the panels impacted at $200 \mathrm{ft} / \mathrm{sec}$ is 59 percent of the strength of the undamaged panels. The damage from the $220 \mathrm{ft} / \mathrm{sec}$ velocity impact causes a significant strength reduction while the delamination associated with the $150 \mathrm{ft} / \mathrm{sec}$ velocity impact does not effect the strength.

A summary of the results for the solid panels that were cyclically loaded is shown in Table 2 and the maximum load as a function of load cycles is shown in figure 17. The diamond symbols are considered runout values and the panels were tested for residual strength. The residual strength results are shown in Table 2. A linear curve fit to the data from the five failed panels is 
shown as a dashed line in figure 17. The coefficients for the curve fit equation are also shown in figure 17. More test results are needed in the low-load high-cycle region of the plot to complete the fatigue life curve.

The average residual strength of the five undamaged solid panels that did not fail after one to three million load cycles is $763 \mathrm{lbs} / \mathrm{in}$. This average residual strength is 107 percent of the baseline strength for the undamaged solid panels. Experimental and analytical out-of-plane deflections at the panel center and quarter point locations for a solid panel (SL12) are shown in figure 18. The calculated out-of-plane deflections have the same general trends as the experimental data but do not have the same magnitudes. This set of experimental curves indicates that a change has occurred in the panel response as indicated by the sudden change in the load-displacement curve when the load is approximately $180 \mathrm{lbs} / \mathrm{in}$. The change in the curve could be caused by a change in mode shape or by a local failure. The out-of-plane deflections are repeatable for the different panels that have not been cyclically loaded. The out-of-plane deflections change in a panel as the number of cycles increases as can be seen in figure 19. The change in center deflection as the number cycles increase to 500,000 cycles is indicated in figure 19. This change in center deflection is typical for all solid panels. It appears as though the material stiffness decreased with increasing number of cycles thus changing the out-of-plane deflection shape. This decrease in material stiffness did not a have a significant effect on the overall panel stiffness as shown in figure 20 . The test-machine head displacement is shown in figure 20 as a function of load for a different number of load cycles applied to panel SL16, which was loaded with 10 million load cycles. All panels started to crack on the crest of the buckle at the panel corners soon after the testing was initiated, and the rate of crack growth varied for the panels. For the damaged panels, the crack propagated to the damage site and stopped for a period of time before continuing to propagate past the damage site. Crazing of the matrix occurred at various locations adjacent to the steel load introduction tabs.

Generally, the solid panels failed by tearing along the load introduction tabs as shown in figure 8 . The failure modes for each solid panel are summarize in Table 2 as a combination of letters shown in figure 8 . Photographs of two failure modes are shown in figures 21 and 22. Laminate failure occurred in the laminate shown in figure 21 , which is typical of a diagonal tension failure. Failure of a damaged panel is shown in figure 22 and extends along two sides and through the impact damage site.

\section{$\underline{\text { Sandwich Panels }}$}

Selected sandwich panels were subjected to lowvelocity impact damage and photographs of the damaged sandwich panels are shown in figures 23 and $24 \mathrm{for}$ impact velocities of $150 \mathrm{ft} / \mathrm{sec}$ and $220 \mathrm{ft} / \mathrm{sec}$, respectively. The damaged areas for the $150 \mathrm{ft} / \mathrm{sec}$ impact are less than 0.25 square inches. The damage areas for the panels that were perforated with a 0.50 inch-diameter sphere are less than 0.6 square inches.

The initial buckling loads are better defined for the sandwich panels than for the solid panels. A summary of the sandwich panel buckling loads is shown in figure 25. The average buckling load for the undamaged panels is $91 \mathrm{lbs} / \mathrm{in}$ and the average buckling load for the panels damaged at $150 \mathrm{ft} / \mathrm{sec}$ is $88 \mathrm{lbs} / \mathrm{in}$. Panels damaged at $220 \mathrm{ft} / \mathrm{sec}$ buckled at 66 lbs/in or a 27 percent lower load than the undamaged panels. The $91 \mathrm{lbs} / \mathrm{in}$ buckling load for the undamaged panels is 58 percent of the buckling load predicted by the STAGS linear buckling analysis. The strain gage results for panel SW1 are shown in figures 26 and 27. Gages 1 and 4 (figure 26) are parallel to the buckle pattern and indicate a tensile strain until failure. The results of the STAGS nonlinear analysis are shown by the dashed lines in figure 26 and 27. Strains shown in figure 27 are for gages 3 and 6 which are normal to the buckle pattern. The strains start diverging at approximately $80 \mathrm{lbs} /$ in which is considered to be the buckling load. At 225 to $240 \mathrm{lbs} / \mathrm{in}$ and $550 \mathrm{lbs} / \mathrm{in}$ this panel appears to change buckling modes. The STAGS analysis predicted a mode change at $270 \mathrm{lbs} / \mathrm{in}$ as shown in figure 27 . The predicted strain normal to the buckle pattern has the same trends as the experimental strain. These strain results are typical of all of the static tests of the sandwich panels. The experimental and predicted out-of-plane deflections for the center (LVDT 2) and the quarter points (LVDT 1 and 3) of sandwich panel number SW8 are shown in figure 28 . The experimental results are from the first static load prior to the start of cyclic loading. A mode change appears to occur at approximately $300 \mathrm{lbs} / \mathrm{in}$ for panel SW8. The analysis predicts a mode change at 270 $\mathrm{lbs} / \mathrm{in}$ as indicated by the dashed curves in figure 28 . Good correlation with the analysis is observed up to 60 Ibs/in. Plots of the test-machine head displacement are shown in figure 29 as a function of load. Panels SW 1 and SW2 are undamaged and have nearly the same response, while the damaged panel SW6 has larger displacements but its stiffness appears to match the undamaged panels. A load decrease is present in all of the curves and corresponds to the mode change observed in the strain gage data. A summary of the 
static strengths of the panels are shown in figure 30 . The average strength of the panels impacted at 150 $\mathrm{ft} / \mathrm{sec}$ is $661 \mathrm{lbs} / \mathrm{in}$ while the average strength of the undamaged panels is $670 \mathrm{lbs} / \mathrm{in}$. The average strength of the panels impacted at $200 \mathrm{ft} / \mathrm{sec}$ is $489 \mathrm{lbs} / \mathrm{in}$ or 73 percent of the undamaged panel strength. The strength of the undamaged sandwich panels is 95 percent of the strength of the undamaged solid panels while the sandwich panels impacted at $150 \mathrm{ft} / \mathrm{sec}$ are 93 percent as strong as the solid panels. The sandwich panels impacted at $220 \mathrm{ft} / \mathrm{sec}$ are 16 percent stronger than the solid panels.

A summary of the sandwich panels that were cyclically loaded is shown in Table 3 and the maximum loads at failure are shown in figure 31 as a function of number of load cycles to failure. A linear curve fit to the data from the five failed panels (triangle symbols) is shown as a dashed line in figure 31 . The coefficients for the curve fit equation are also shown in figure 31 . The diamond symbols represent runout values and these panels were tested for residual strength. The residual strength results are also shown in Table 3 . More test results are needed in the low-load high-cycle range of the plot to produce a full fatigue life curve for the sandwich panels. The average residual strength of the four undamaged sandwich panels with one to four million load cycles is $749 \mathrm{lbs} / \mathrm{in}$. This residual strength is 112 percent of the baseline strength of the undamaged sandwich panels. A comparison of the sandwich panel results in figure 31 with the solid panel results in figure 17 indicates the sandwich panels have a shorter fatigue life than the solid panels. The out-ofplane deflections for the sandwich panels also change as the number of cycles increases as they did for the solid panels (see figure 32 ). All sandwich panels cracked and failed in a manner similar to the solid panels and most of the sandwich panels exhibited a fold as shown in figure 33 which was set permanently in the panel. A summary of all the failure modes is given in Table 3 using the notation of figure 8. A photograph of a failed sandwich panel is shown in figure 34 where a crack extends along the panel edge and another crack extends from the corner parallel to the fiber direction.

Low-cycle fatigue - A summary of the results for the sandwich panels that were cycled with increasing loads is given in Table 4. The strain gage and LVDT data for these panels were recorded for both the load and unload cycles. All strain gage and LVDT response curves returned to their starting point for each load cycle. The load as a function of stroke for three cycles, and load to failure for the undamaged panel and the panel damaged at $220 \mathrm{ft} / \mathrm{sec}$ are shown in figures 35 and 36. The hysteresis in the data shown in figures 35 and 36 is considered insignificant since all of the strain gage response curves returned to their starting points. Some of the variation in the data shown in the figures could be the result of tolerances in the in-plane test fixture and load frame. There is no obvious reason for the slopes of the curves to be different in figures 35 and 36.

\section{Summary}

The postbuckling strength of thin solid and sandwich Kevlar-epoxy panels have been determined for both undamaged and damaged conditions. Panel fatigue life of the solid and sandwich panels has also been determined for both undamaged and damaged conditions. Low-velocity impact damage caused by a 0.5 -inch-diameter aluminum ball with a velocity of 150 $\mathrm{ft} / \mathrm{sec}$ has no effect on the static strength of the solid or sandwich panels while an impact with a velocity of 220 $\mathrm{ft} / \mathrm{sec}$ reduces the panel strength significantly. The static strength of the sandwich panels are approximately five percent lower than the static strength of the solid panels. The fatigue life of the sandwich panels is shorter than the fatigue life of the solid panel. Cyclically loading solid and sandwich panels did not significantly affect the panel residual strength. The effect of hysteresis on the sandwich panel load cycles is not significant.

\section{References}

1. Farley, G. L. and Baker, D. J., "In-plane Shear Test of Thin Panels," Experimental Mechanics, Vol. 23, No. 1, March 1983, pp. 81-88.

2. Brogan, F. A, Rankin, C. C., and Cabiness, $H$. D., "STAGS Users Manual, " Lockheed Palo Alto Research Laboratory, Report LMSC P032594, 1994. 
Table 1. Summary of Levlar-49-5208 Material Properties.

\begin{tabular}{cc}
\hline \hline Property & Value \\
\hline $\mathrm{E}_{11}$ & $4.7 \mathrm{msi}$ \\
$\mathrm{E}_{22}$ & $3.34 \mathrm{msi}$ \\
$\mathrm{G}_{12}$ & $0.326 \mathrm{msi}$ \\
$\sigma_{1}$ & $90 \mathrm{ksi}$ \\
$\sigma_{2}$ & $62 \mathrm{ksi}$ \\
$\tau_{12}$ & $8.5 \mathrm{ksi}$ \\
$\varepsilon_{11}$ & $0.017 \mathrm{in} / \mathrm{in}$ \\
$\varepsilon_{22}$ & $0.014 \mathrm{in} / \mathrm{in}$ \\
$\gamma_{12}$ & .058 \\
$v$ & 0.18 \\
\hline \hline
\end{tabular}

Table 2 - Summary of Experimental Results for Solid Panels.

\begin{tabular}{cccccccc}
\hline \hline $\begin{array}{c}\text { Panel } \\
\text { No. }\end{array}$ & $\begin{array}{c}\text { Impact velocity, } \\
\mathrm{ft} / \mathrm{sec}\end{array}$ & $\begin{array}{c}\text { Test } \\
\text { Type }\end{array}$ & $\begin{array}{c}\text { Buckling, } \\
\text { lbs/in }\end{array}$ & $\begin{array}{c}\text { Maximum } \\
\text { Load, } \\
\text { lbs/in. }\end{array}$ & $\begin{array}{c}\text { Cycles, } \\
\text { K }\end{array}$ & $\begin{array}{c}\text { Strength } \\
\text { lbs/in }\end{array}$ & $\begin{array}{c}\text { Failure } \\
\text { Locations } \\
\text { (See fig. 8) }\end{array}$ \\
\hline SL1 & 0 & S & 20 & & & 723 & E \\
SL2 & 0 & S & UD $^{\text {b }}$ & & & 545 & E \\
SL3 & 0 & S & UD & & & 856 & A, D \\
SL4 & 150 & S & UD & & & 774 & E \\
SL5 & 153 & S & UD & & & 645 & C, E \\
SL6 & 224 & S & UD & & & 415 & D \\
SL7 & 220 & S & 19 & & & 425 & D \\
SL8 & 0 & F & 14 & 369 & 385 & & A, B \\
SL9 & 150 & F & UD & 369 & 102.1 & & F \\
SL10 & 150 & F & 10 & 369 & 638.7 & & C, D, F \\
SL11 & 220 & F & 13 & 270 & 100 & & B, C \\
SL12 & 0 & F & DL & 576 & 100 & & A, B, D \\
SL13 & 221 & F & 15 & 307 & 1000 & 479 & D, F, G \\
SL14 & 0 & F & 12 & 369 & 1000 & 810 & B, F, G \\
SL15 & 0 & F & 22 & 200 & 3000 & 857 & A, D, F \\
SL16 & 0 & F & 25 & 200 & 10000 & 804 & A, D, F \\
SL17 & 0 & F & UD & 461 & 1005 & 660 & F \\
SL18 & 0 & F & 25 & 307 & 5468 & 685 & A, B \\
SL19 & 0 & F & DL & 480 & 20.1 & 825 & \\
\hline \hline
\end{tabular}

Test Type: $S=$ Static; $F=$ Cyclic

${ }^{b}$ UD - Buckling not defined

${ }^{c}$ DL - Data lost

d Test machine servo valve failure 
Table 3 - Summary of Experimental Results for Sandwich Panels.

\begin{tabular}{cccccccc}
\hline $\begin{array}{c}\text { Panel } \\
\text { No. }\end{array}$ & $\begin{array}{c}\text { Impact velocity, } \\
\text { ftsec. }\end{array}$ & $\begin{array}{c}\text { Test } \\
\text { Type }\end{array}$ & $\begin{array}{c}\text { Buckling, } \\
\text { lbs/in. }\end{array}$ & $\begin{array}{c}\text { Maximum } \\
\text { Load, } \\
\text { lbs/in }\end{array}$ & $\begin{array}{c}\text { Cycles, } \\
\text { K }\end{array}$ & $\begin{array}{c}\text { Strength, } \\
\text { lbs/in. }\end{array}$ & $\begin{array}{c}\text { Failure } \\
\text { Locations } \\
\text { (See fig. 8) }\end{array}$ \\
\hline SW1 & 0 & S & 80 & & & 682 & B, C \\
SW2 & 0 & S & 80 & & & 657 & C \\
SW3 & 153 & S & DL $^{\text {c }}$ & & & 654 & A, B \\
SW4 & 154 & S & DL & & & 668 & F \\
SW5 & 258 & S & DL & & & 459 & D \\
SW6 & 266 & S & UD & & & 518 & D \\
SW7 & 0 & F & 75 & 415 & 14.1 & & C, F \\
SW8 & 0 & F & 75 & 415 & 39.9 & & A, B \\
SW9 & 155 & F & 80 & 415 & 23.2 & & E \\
SW10 & 151 & F & 95 & 415 & 39.7 & & A \\
SW11 & 262 & F & 57 & 305 & 223.9 & & A, B \\
SW12 & 264 & F & 75 & 305 & 1000 & 463 & D \\
SW13 & 0 & F & DL & 230 & 4000 & 665 & C \\
SW14 & 0 & F & 95 & 160 & 1000 & 748 & B, C \\
SW15 & 0 & F & 110 & 192 & 1000 & 808 & B, F \\
SW16 & 0 & F & 120 & 184 & 2000 & 775 & F \\
SW17 & 0 & F & 90 & 195 & DL & & F, C \\
\hline \hline
\end{tabular}

Test Type: $\mathrm{S}=$ Static; $\mathrm{F}=$ Cyclic

${ }^{b}$ UD - Buckling not defined

${ }^{c}$ DL - Data lost

Table 4 - Summary of Experimental Results for Low-Cycle Fatigue Sandwich Panels.

\begin{tabular}{ccccc}
\hline \hline $\begin{array}{c}\text { Panel } \\
\text { No. }\end{array}$ & $\begin{array}{c}\text { Impact velocity, } \\
\mathrm{ft} / \mathrm{sec} .\end{array}$ & $\begin{array}{c}\text { Test } \\
\text { Type }^{\mathrm{a}}\end{array}$ & $\begin{array}{c}\text { Strength, } \\
\text { lb/in. }\end{array}$ & $\begin{array}{c}\text { Failure } \\
\text { Location } \\
\text { (See fig. 8) }\end{array}$ \\
\hline LCF1 & 0 & LCF & 615 & C, F \\
LCF2 & 153 & LCF & 584 & C, F \\
LCF3 & 262 & LCF & 506 & \\
\hline \hline
\end{tabular}

a Test Type: $\mathrm{LCF}=$ Low Cycle Fatigue 


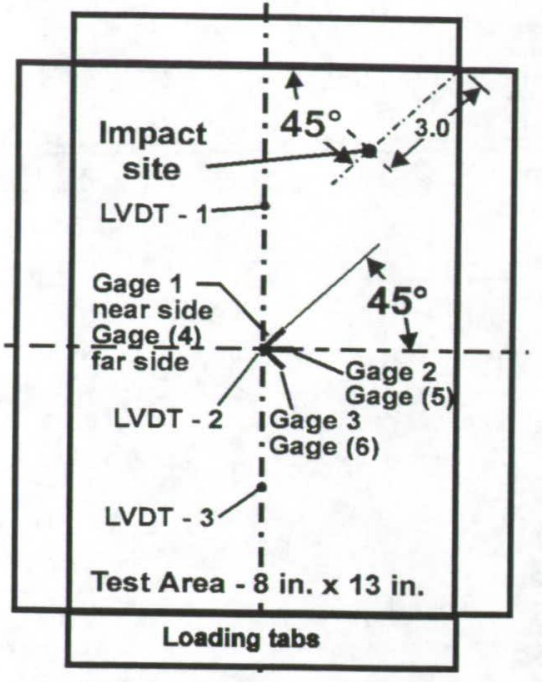

Figure 1. - Location of strain gages, impact site, and displacement transducers (LVDT).

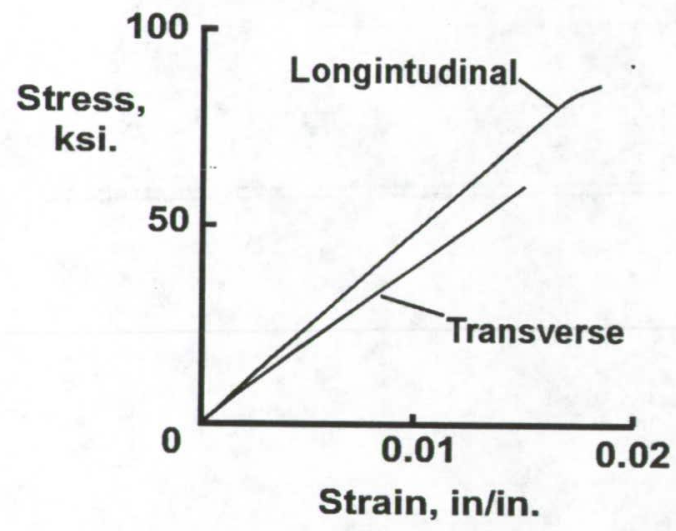

Figure 2. - Stress-strain curves for Kevlar-49-epoxy material used for the panels.

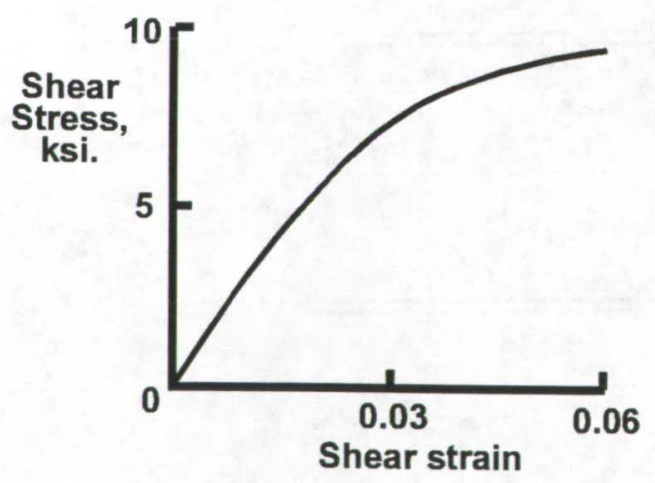

Figure 3. - Shear-stress-shear-strain curve for Kevlar-49-epoxy material used for the panels.

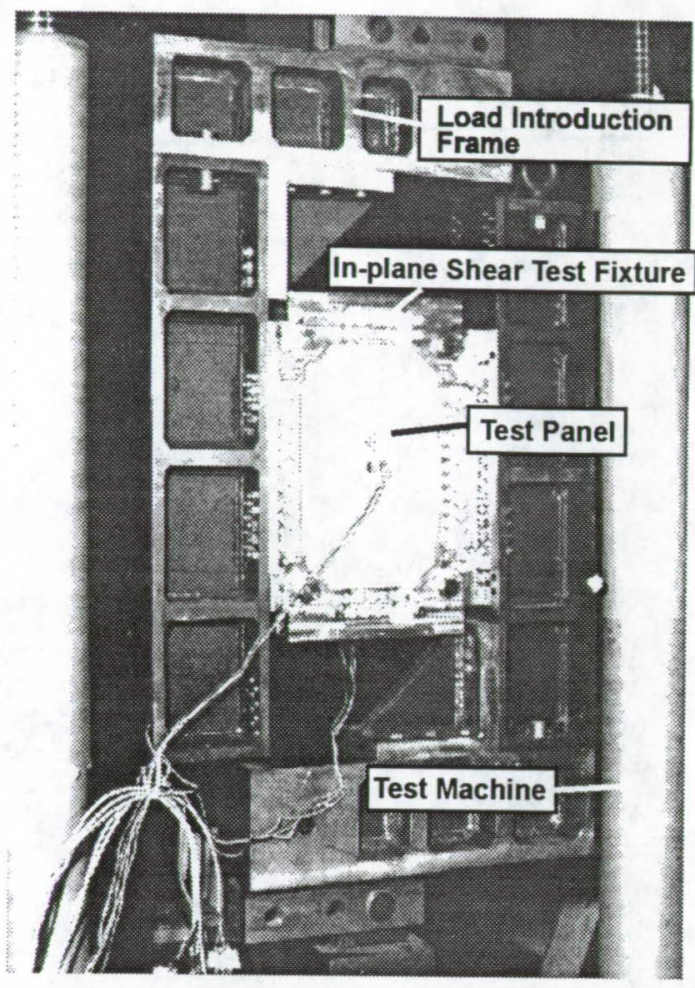

Figure 4. - Test setup with panel.

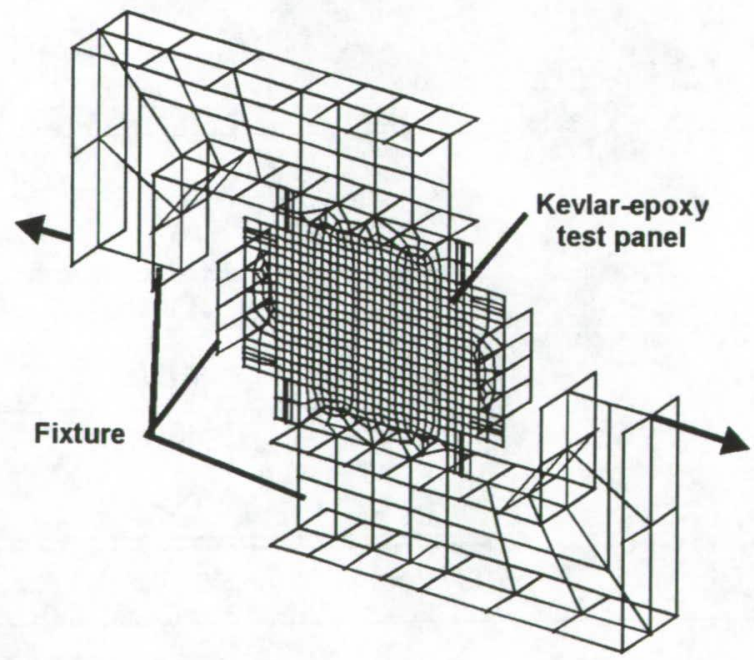

Figure 5. - STAGS finite element model of Kevlarepoxy panel and loading frame. 


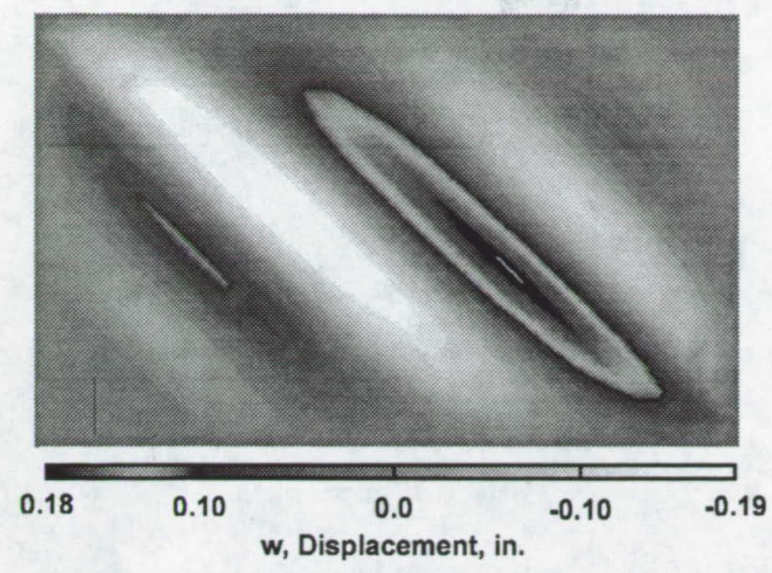

Figure 6. - Out-of-plane displacement predictions for $\mathbf{N}_{\mathrm{xy}}=\mathbf{8 5 0} \mathrm{lbs} / \mathrm{in}$.

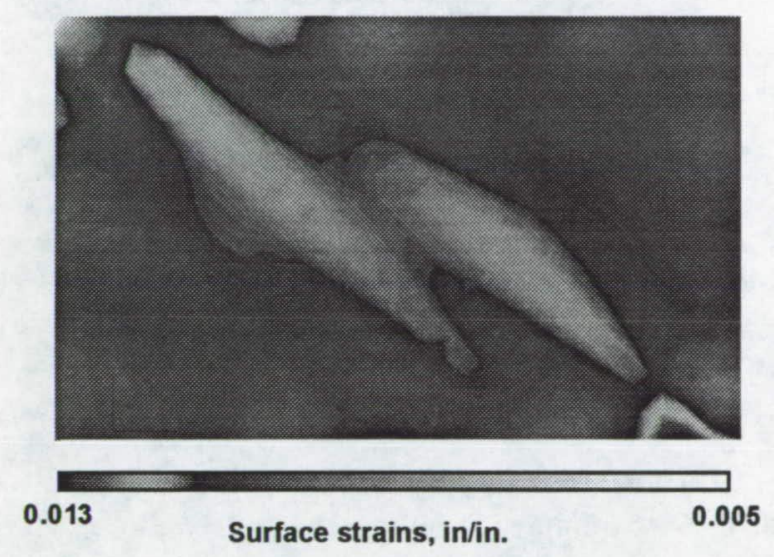

Figure 7. - Surface strain predictions, parallel to the buckle pattern for $\mathrm{Nxy}=\mathbf{8 5 0} \mathrm{lbs} / \mathrm{in}$.

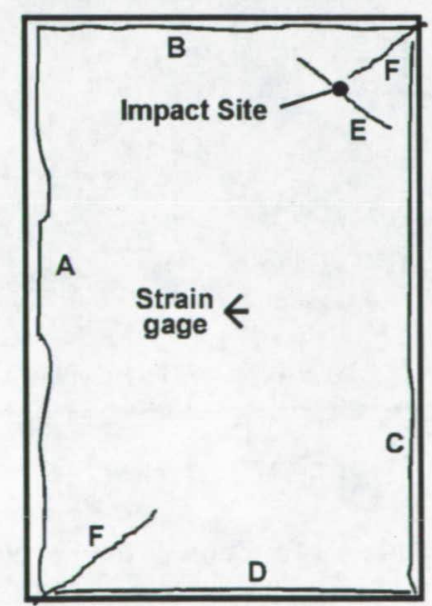

Figure 8. - Location of failure sites.

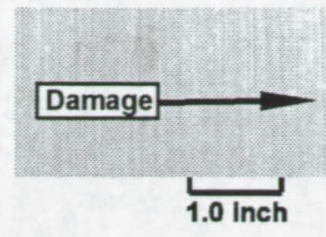

Figure 9. - Damage in solid panel impacted at 150 $\mathrm{ft} / \mathrm{sec}$.

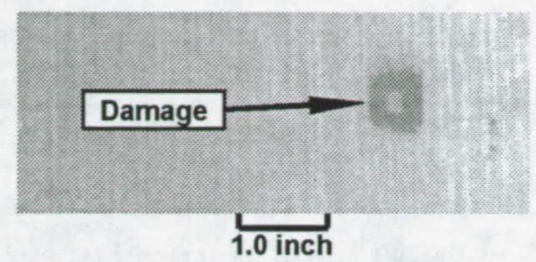

Figure 10. - Damage in solid panel impacted at 220 $\mathrm{ft} / \mathrm{sec}$.

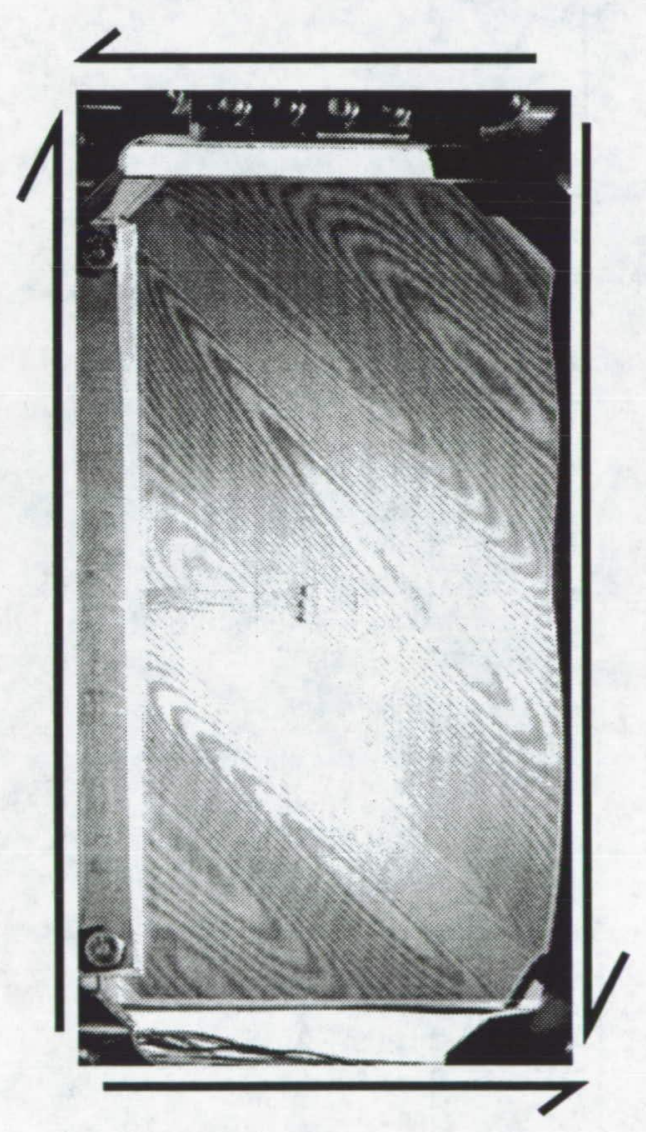

Figure 11. - Out-of-plane deflections as determined from moire pattern for $\mathrm{N}_{\mathrm{xy}}=851 \mathrm{lbs} / \mathrm{in}$. 


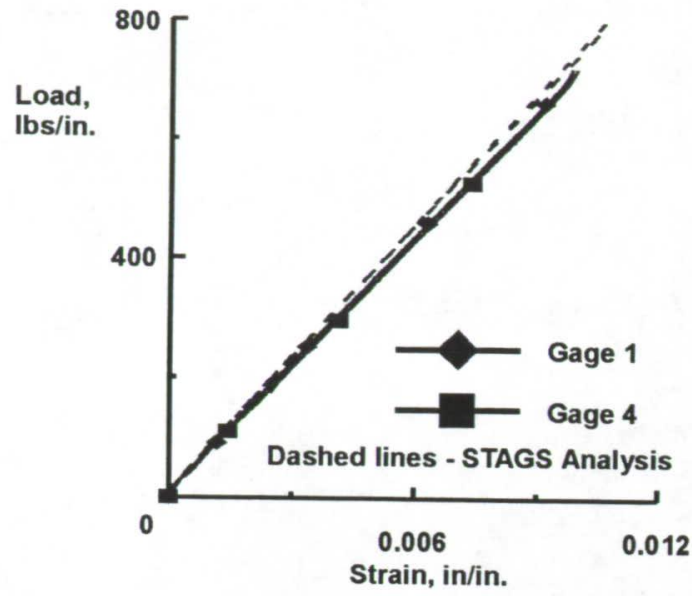

Figure 12. - Comparison of experimental and predicted strain, parallel to the buckle pattern.

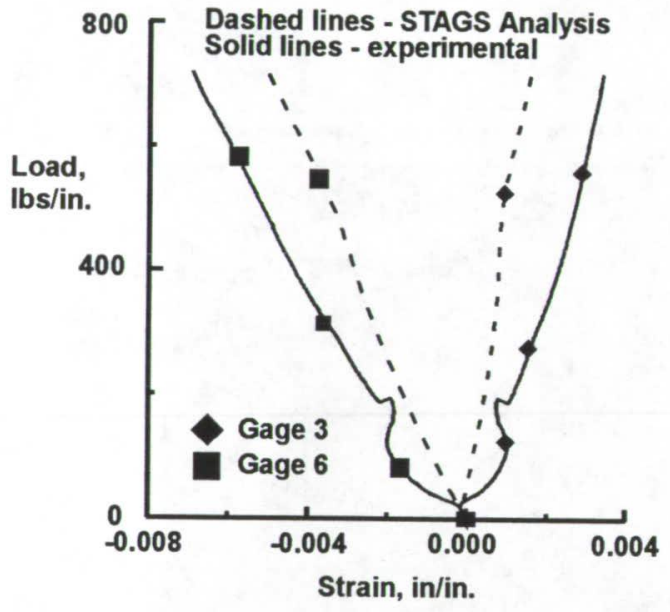

Figure 13. - Comparison of experimental and predicted strain normal to the buckle pattern.

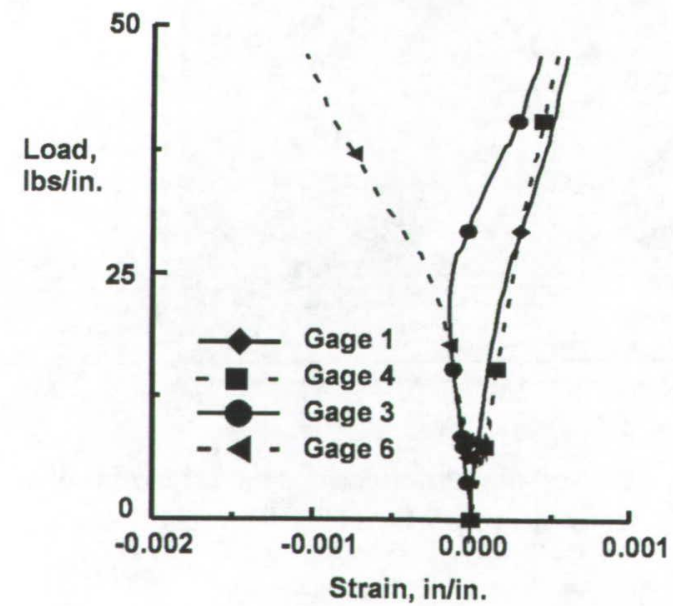

Figure 14. - Detail of experimental strain to a load of $45 \mathrm{lbs} / \mathrm{in}$.

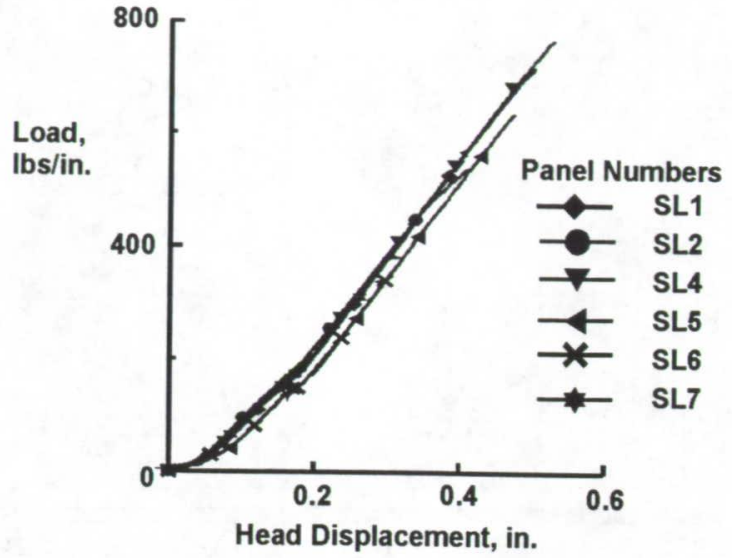

Figure 15. - Comparison of head displacements for solid panels.

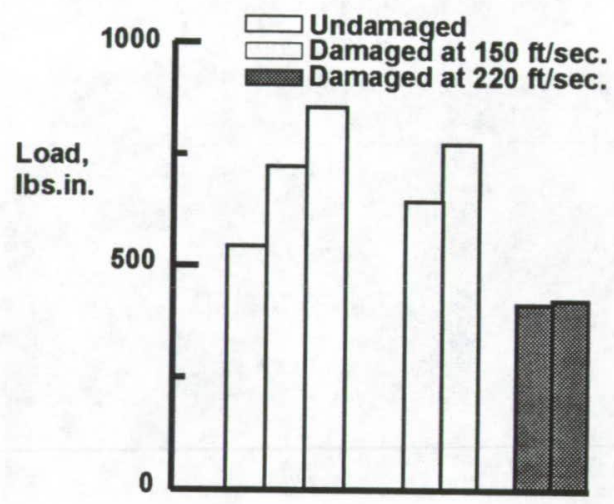

Figure 16. - Summary of failure strengths for solid panels.

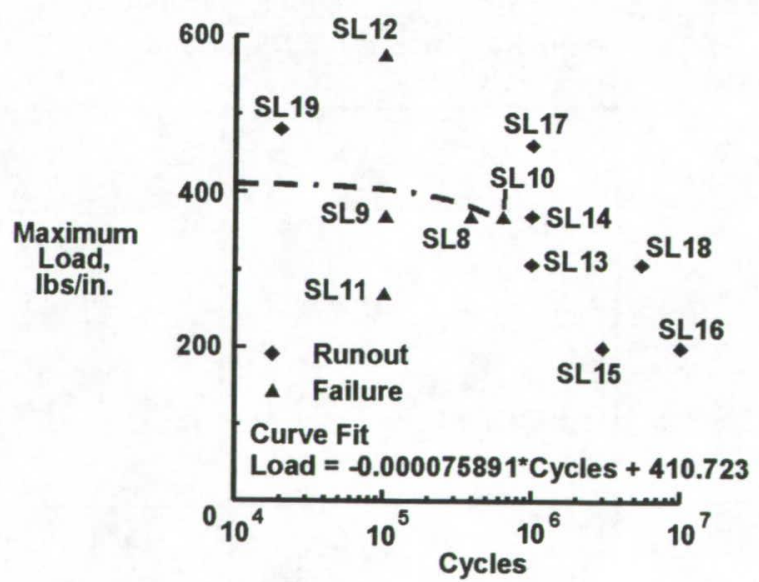

Figure 17. - Load as a function of load cycles for solid laminates. 


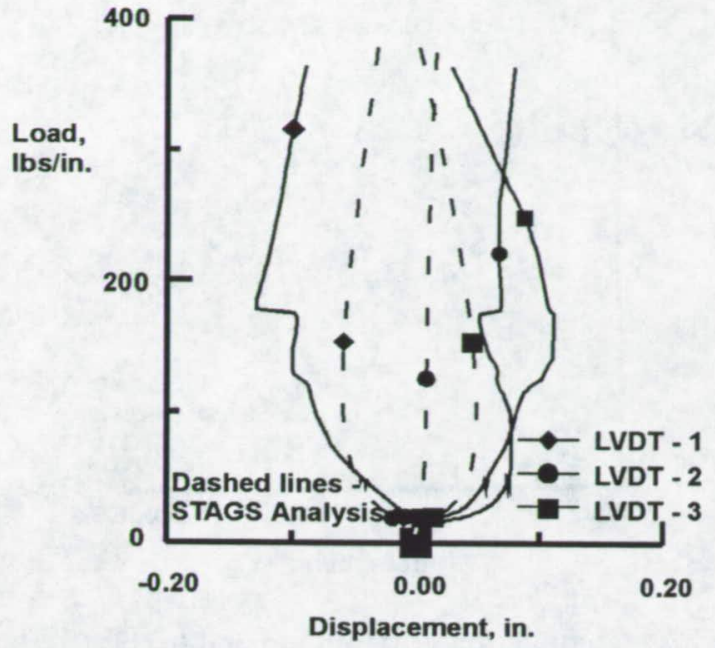

Figure 18. - Comparison of out-of-plane displacements with analysis on solid panels.

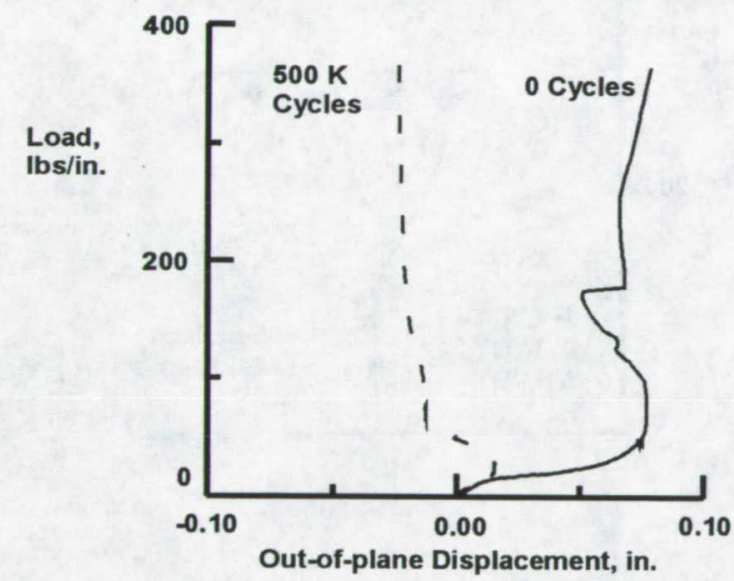

Figure 19. - Comparison of center out-of-plane displacements for different cycle accumulation on a solid panel.

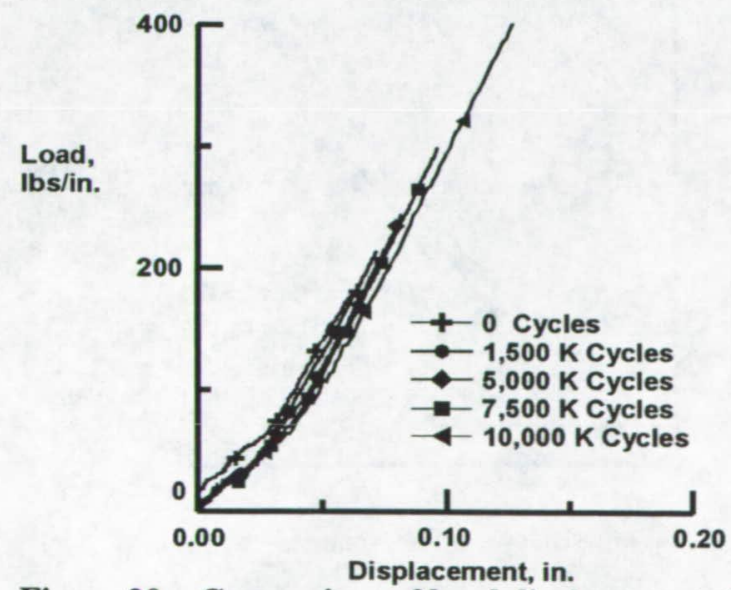

Figure 20. - Comparison of head displacements for different number of cycles on panel SL16.

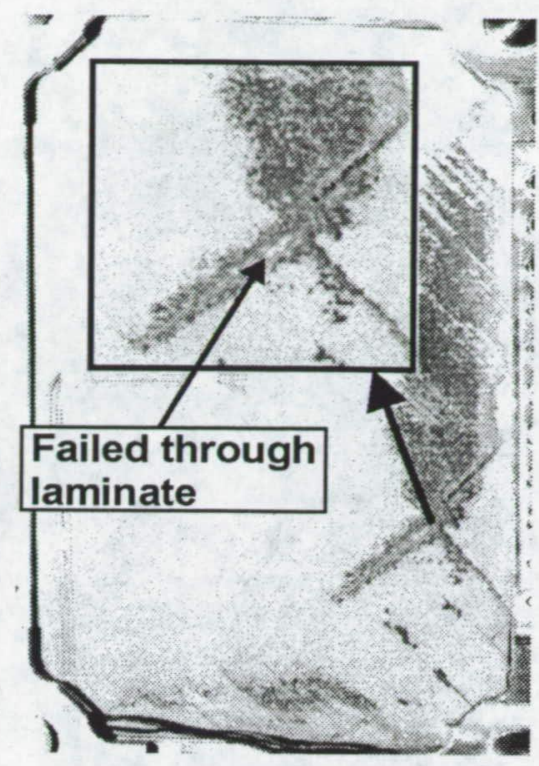

Figure 21. - Photograph of failed panel SL3.

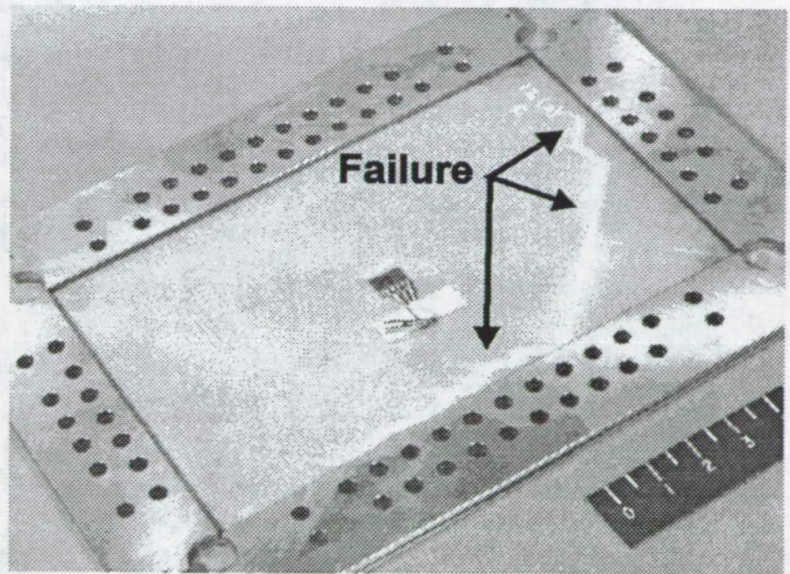

Figure 22. - Failure of damaged panel SL5.

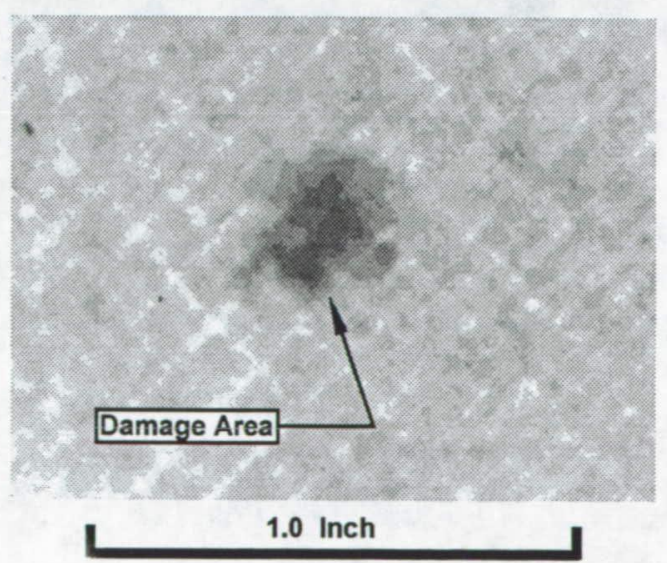

Figure 23. - Damaged sandwich panel impacted at $150 \mathrm{ft} / \mathrm{sec}$. 


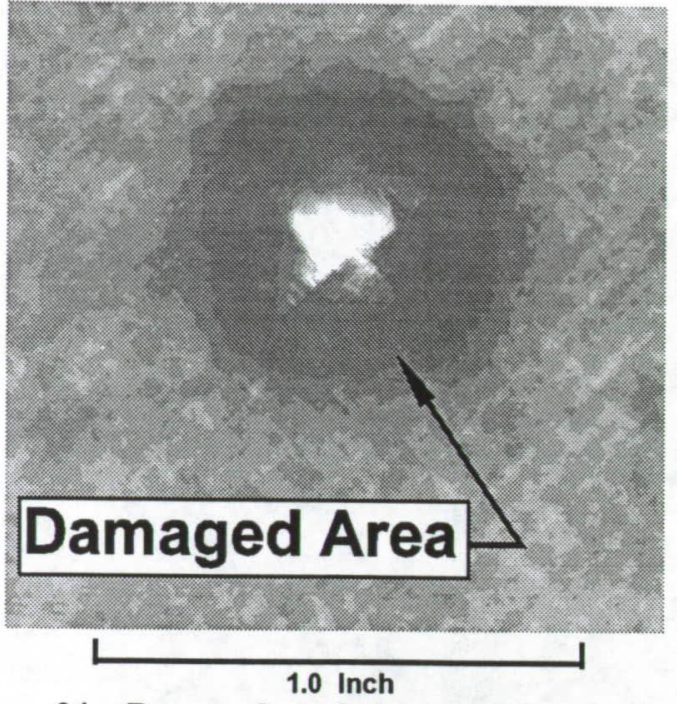

Figure 24. - Damaged sandwich panel impacted at $220 \mathrm{ft} / \mathrm{sec}$.

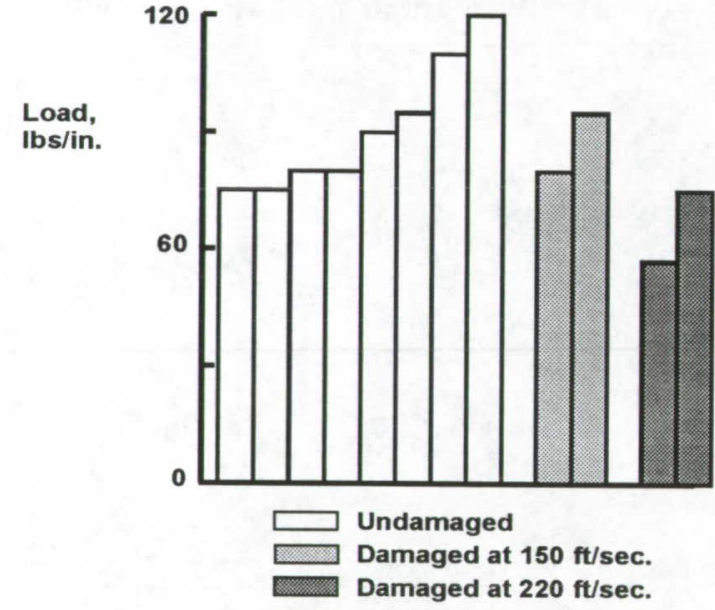

Figure 25. - Summary of initial buckling loads for sandwich panels.

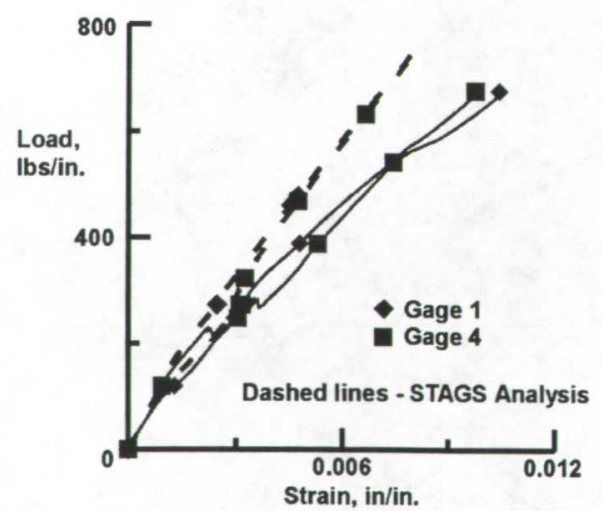

Figure 26. - Comparison of strain parallel to the buckle pattern for Panel SW1.

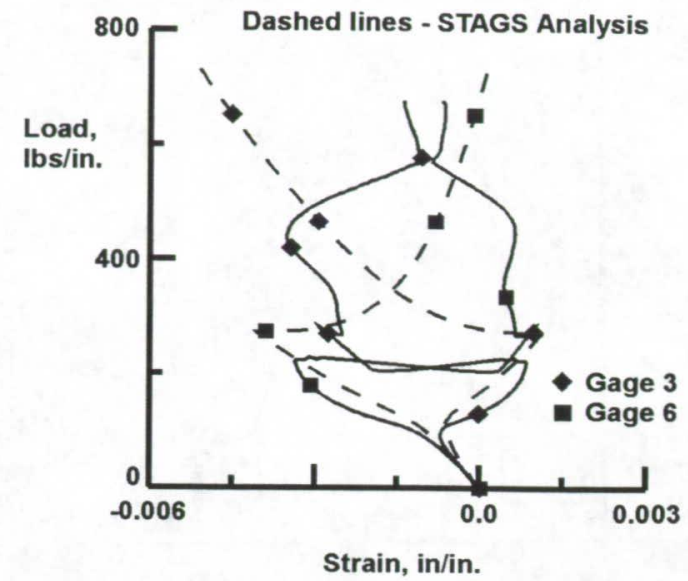

Figure 27. - Comparison of strain normal to the buckle pattern for Panel SW1.

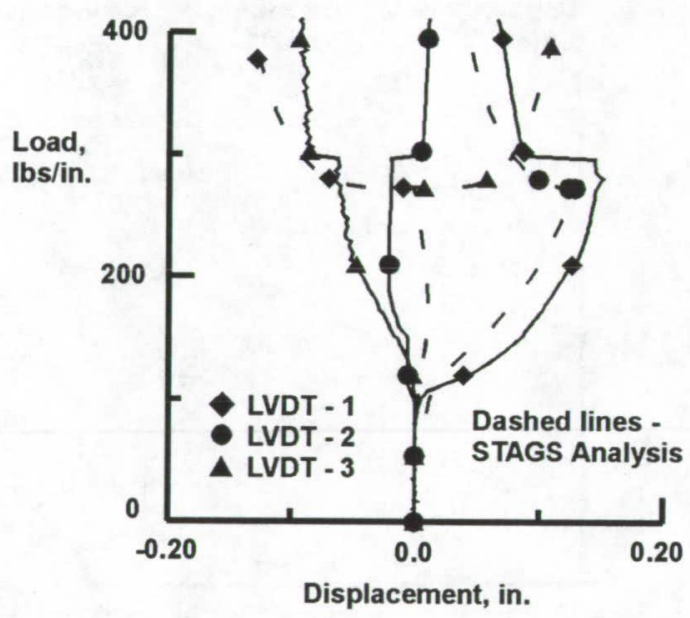

Figure 28. - Comparison of out-of-plane displacements for Panel SW8.

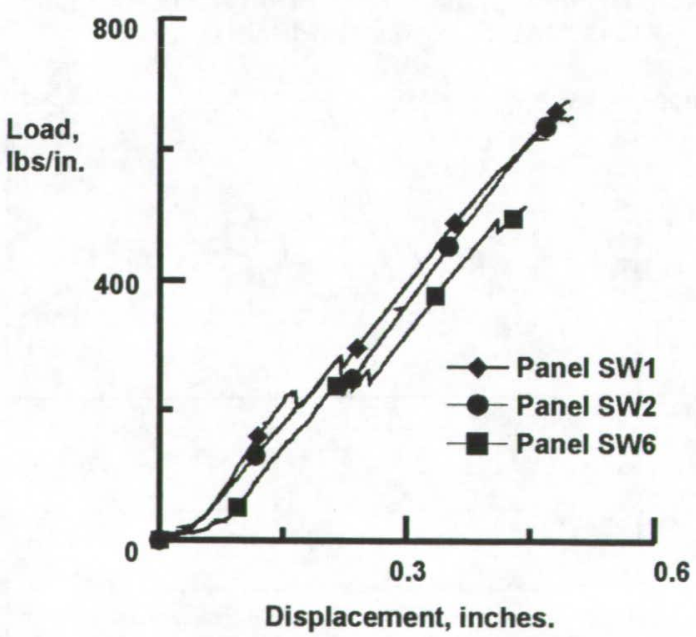

Figure 29. - Comparison of head displscements for sandwich panels. 


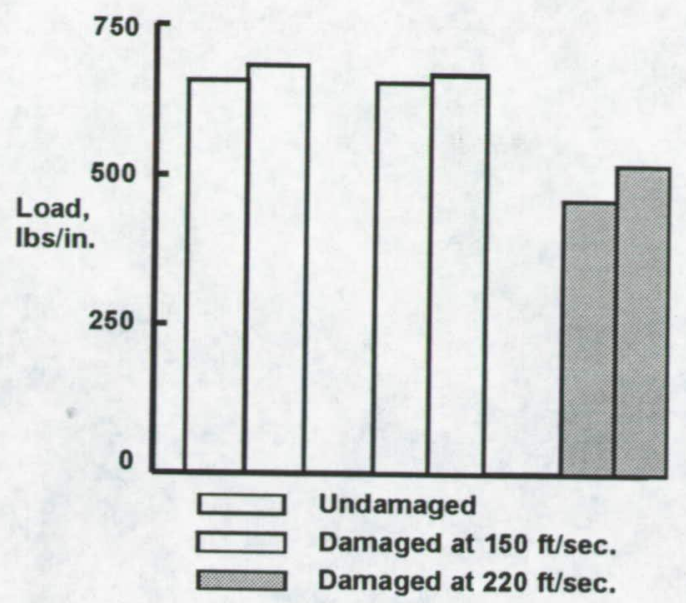

Figure 30. - Summary of ultimate strength for sandwich panels.

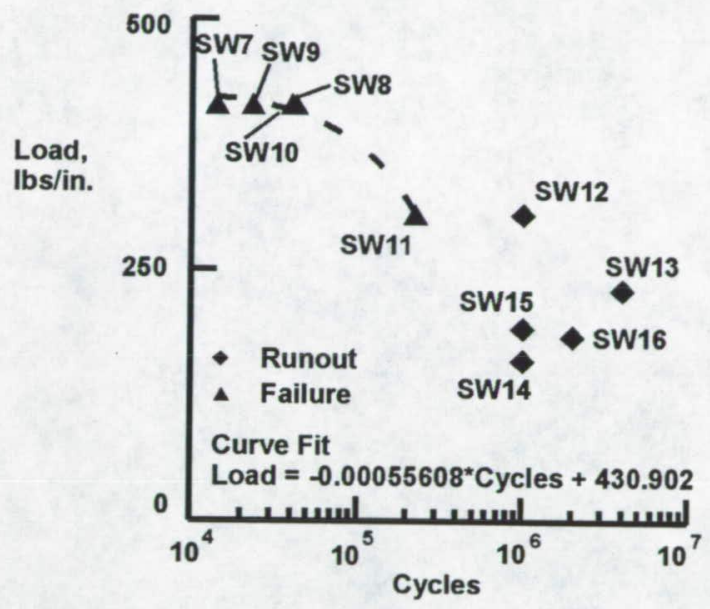

Figure 31. - Load as a function of load cycles for sandwich laminates.

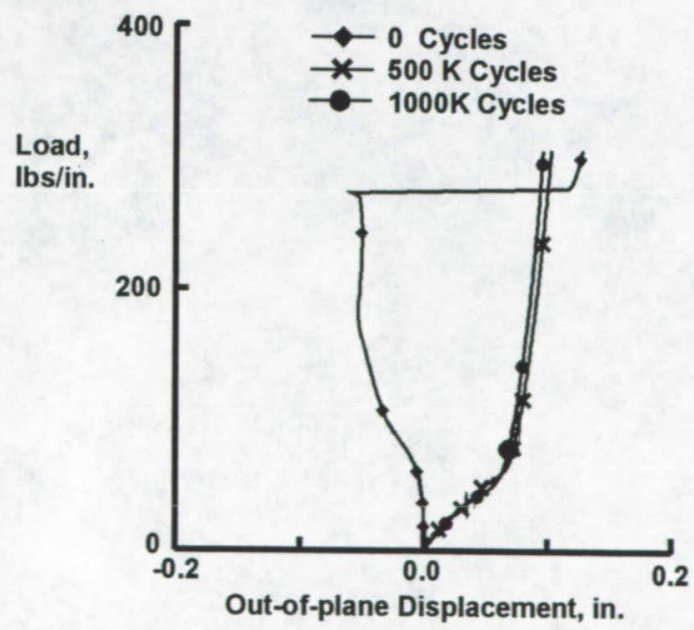

Figure 32. - Comparison of out-of-plane deflections for sandwich Panel SW11.

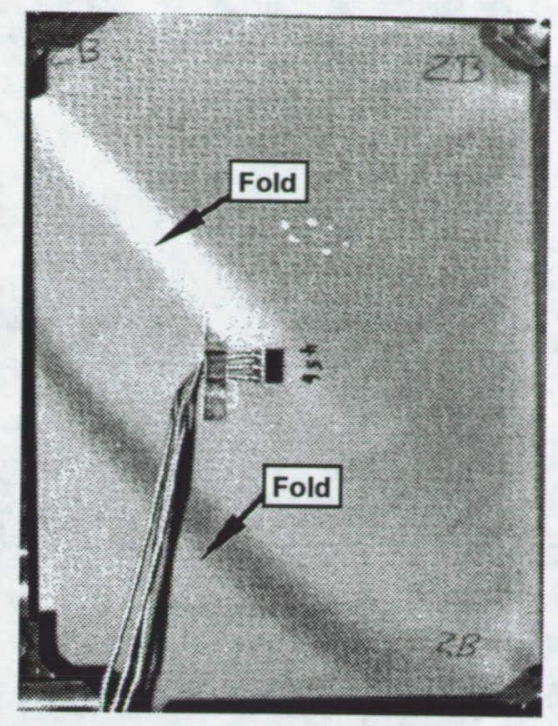

Figure 33. - Photographs of folds in sandwich panel.

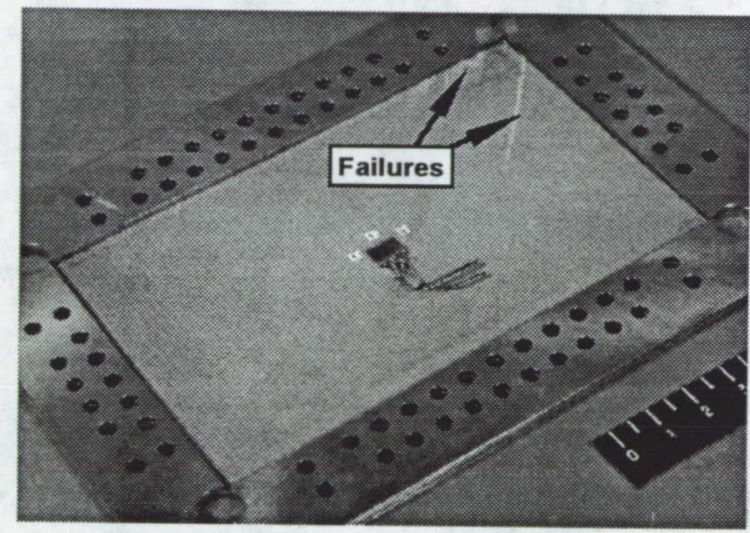

Figure 34. - Failures in sandwich panel.

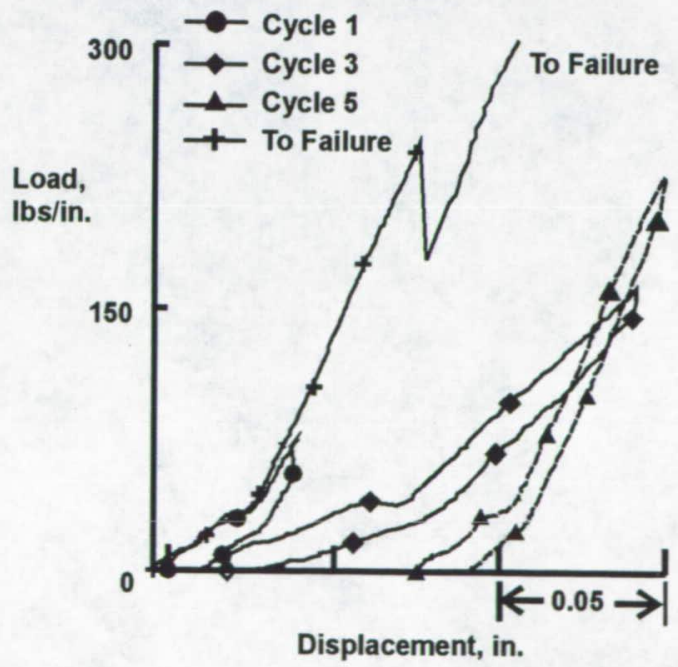

Figure 35. - Comparisons of head displacements for Panel LCF1 with no damage. 


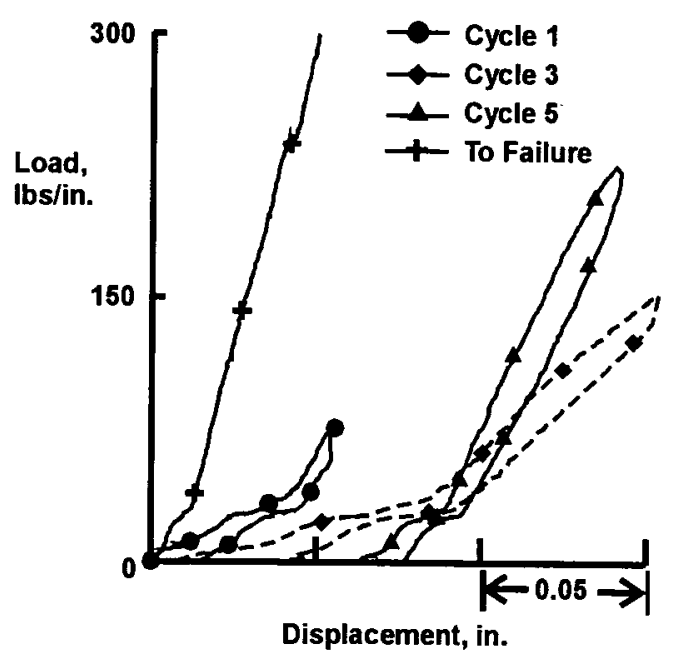

Figure 36. - Comparison of head displacements for Panel LCF3 that was damaged at 220 $\mathrm{ft} / \mathrm{sec}$. 